\title{
A STUDY OF AUTOBIOGRAPHICAL APPROACH AND UNDERSTANDING
}

\author{
Dr. A.V.S. Jayaannapurna \\ REVA.University, Bengalore, India.
}

\begin{abstract}
Autobiography is a unique and fascinating document that can maintain its value in history as first person narrative while providing a specific identity of his /her ownself in literary research.Autobiographical works are by nature subjective. However, the power of personality is inseperable from the subjectivity of the author in an autobiography. Autobiographies give novel approach and in sight in to the way how individuals define themselves and understand their own experiences. Memory, identity and experience are the pillars of reason in autobiographical subjectivity.
\end{abstract}

Autobiography is a unique and fascinating document that can maintain its value in history as first person narrative while providing a specific identity of his /her ownself in literary research.. Autobiographical works are by nature subjective. However, the power of personality is inseperable from the subjectivity of the author in an autobiography. Autobiographies give novel approach and in sight in to the way how individuals define themselves and understand their own experiences. Memory, identity and experience are the pillars of reason in autobiographical subjectivity.

Memory: The author of an autobiography reassembles the scattered elements of his individual self and regroups them in a comprehensive sketch. The author is both self and more than self; He exists both within and beyond social space and historical time. Men and women become fully human only by reaching the limits of personal or collective identity. Such belief provides common ground for a variety of spiritual narratives written out of different religious traditions, but within our largely secularized culture.

Individuals narrate about their life events in more general and summarized language, more or less, avoid recalling specific unforgettable and identifiable moments in the passage of chronological time. Similarly, individuals can, scan and provide unadorned facts, statistics and descriptions that characterize people, events, or time periods, without a pointer to the sensory and emotional shade of a specific recollection.

Even when individuals are disclosing autobiographical narrative component, there is still a difference between accounts of recent events that have yet to be fully processed and linked to the long term self and events from the past that have been rehearsed and embedded in the long term self's network of unconscious and conscious thoughts and affective associations.

Subjectivity is an empirical and pragmatic notion in linguistic and literary studies. The onset of $21^{\text {st }}$ century brought to lime light the dreams and ambitions of individual and his own mental, physical and spiritual space of freewill. Subjectivity can be termed as retrieval in to self. It is a phenomenal episode to a person's reflection of self in experiencing certain unusual and unparalleled personal backdrops. Each individual self based on these elements form into cohesive identity of self, likes and dislikes, thoughts and actions mark an individual. Memory is a flexible constructive past and positively not a perfect copy of the past. Social theorists argue that recollection is constructed here. At certain point of time, memories are distorted. Imagination information without logic, rapidly lost at a shopping mall, .memory going back on critical events in their life. The autobiographer will often recapitulate on special aspects of his life, such as the influences that moulded him or the services that he rendered to what he most cared about. 


\section{Authenticity and truth}

Though the prior aim and intention of autobiographers is naturally authenticity, they, like historians, neither chronolize nor review all that happened in a diary form. In addition, their human and sensual experiences are not expected to reveal all about themselves on the autobiographic platform. Autobiographers scribble their life story in the manner they choose to shape. They are at liberty to choose the mainstream events what they want to include or omit. They can simplify or amplify an event on the basis of their own shades of memory. The way he or she organizes and arranges the events of the story shows what the author considers important.

\section{Accounting and identity self-reflection}

The aesthetic experiences take shape and coin into memories of accountability which is a natural sequence of auto writing. The author depicts truths about himself through his experiences and the contemporary self is a pointer to the narrated self in the process of scripting. The past events says much about whom he introspects and a process of elimination takes place with the suspension of certain events to avoid controversial analysis of the self. The author wants to justify his or her past actions to the reader. Accounting and self-reflection are touchstones of autobiography. Quigley says that a related but not identical narrator and protagonist are integral to the process of self-justification (Quigley 107). The author establishes relationships to him or herself in order to show causality. For example, because the narrator and the protagonist are not identical, the narrator has "the ability to treat the self as other creat [ing] the occasion for self-regard and editing [because of] the distance between self-now and self-then" (Quigley 107).

There is also a relationship between the reader and the author. Because of judging past actions as right or wrong, the narrator establishes to the reader that they share common norms. The narrator speaking in the autobiography "is always moral, even if the protagonist of the narrative is not" (Quigley 107). This relating is then evaluated socially according to whether actions are appropriate or inappropriate or surprising or normal (Quigley 64, 106-7, 155). The protagonist must share a common identity in the narrative to be considered and marked as an autobiography.

\section{Subjective and objective approach}

Autobiographies are of paramount importance in cognitive science to understand and analyze the emotional experiences of an author. Overwhelmed by the unflinching thirst to commune with reader and unravel his own hidden realms of past memories, the author tries to better know himself which is a mode of confession too.

While sharing his emotional experiences as tributes to the reader, he can aswell combine the objective and the subjective approach. As observer of certain contemporary social, political national and international events that profoundly shape his own individual self, the objective approach is used by autobiographers where the protagonist is an object of an event or occurrence. Yet its impact on the individual is remarkable in changing his attitudes to a noticeable level

Subjective approach narrates the reflection and sensual appeal of the autobiographer on a social or emotional experience.It has direct appeal and focus on the reader' and create an obsession of shared emotions as if the reader is also as a part of the sensual phenomena.This aesthetic fulfilment unconsciously drive the the reader to be a part in the autobiographic journey of the author .

When using the autobiographical approach, one can discover:

1. Events that may have occurred in the author's life: For example, many authors who often discuss about characters that also face similar problems. For example, Yogananda in his narrative, Autobiography of a yogi, makes a mention about certain yogis and fakirs who had acquired unusual powers.

2. Feelings or beliefs of the author: For example Paramhansa Yogananda shows his beliefs about religion and the philosophical musings in his poems and clearly shows how he is influenced by Indian philosophy. 
3. Events occurring during the time the author lived, such as war or new philosophies: R. .K. Narayan refers to the impact of II world war on the economy of Indian middle class in his autobiography, My Days, a memoir.

Thus, the autobiographical approach and understanding always concerns with the difference between truth and fiction. Researchers are encouraged to recall experiences of the autobiographer from childhood and adulthood, view relationships across their lifespan in judging auto- biographer's narratives. Interviewers are trained to attend to the author's emotional responses around narrative material and to follow up with questions that offer opportunities to make connections across powerful episodes from their lives. Teacher educators have recognized the importance of the individual's lived experiences as relevant to the development of a student, who in turn, imbibe values in the classroom.

\section{References}

1. Pascal Roy. Design and Truth in Autobiography, Harvard University Press, Cambridge, U.S.A.: 1960. Print

2. Quigley Jean, The Grammar of Autobiography: A developmental account. . NJ, US: Lawrence Erlbaum Associates: 2000 web. Google books

3. Eakin, Paul John. How Our Lives Become Stories: Making Selves. Ithaca, N.Y: Cornell University Press, 1999.web.Google books

4. R.K.Narayan, My days A Memoir. First Published 1973 by Viking, Penguin, Putnam Inc., New York.

5. Smith Sidonie, Julia Watson. Reading Autobiography - A Guide for interpreting Life Narratives, University of Minnesota Press, 2010, web..Google books

6. Yogananda, Paramahansa. Autobiography of a Yogi, Yogoda Satsang society of India, calcutta 